\title{
The De-Scent of Sexuality: Should We Smell a Rat?
}

\author{
Jackson Clive $^{1} \cdot$ William Wisden ${ }^{2} \cdot$ Vincent Savolainen $^{1}$ (I)
}

Received: 20 August 2019 / Revised: 14 November 2019 / Accepted: 18 November 2019 / Published online: 5 December 2019 (c) The Author(s) 2019

In their Target Article, Pfau, Jordan, and Breedlove (2019) proposed a connection between the transient receptor potential cation channel 2 gene (TRPC2) and same-sex sexual behavior (SSSB) in primates. This novel theory is an attractive prospect for researchers investigating sexuality in the natural world. The proposal relies on evidence from proximate mechanism studies of TRPC2 knockout (KO) experiments in mice, in which non-functional TPRC2 alters the development of an olfactory sensory structure called the vomeronasal organ (VNO), resulting in an increase in SSSB in both males and females (Axel et al., 2002; Kimchi, Xu, $\&$ Dulac, 2007). In combination with an examination of TRPC2 sequence data and evolutionary relationships across primates, Pfau et al. proposed some hypotheses for the fitness consequences of SSSB in primates. Pfau et al. speculated that primates with multi-male/multi-female societies may have evolved via improved social cohesion facilitated by an increase in SSSB, mediated by non-functional TRPC2, and/or pleiotropy between increased SSSB and reduced same-sex aggression. Here, although we support some of these ideas by providing a more complete examination of $T R P C 2$ in primates, we also advocate greater caution when interpreting available data on SSSB.

Electronic supplementary material The online version of this article (https://doi.org/10.1007/s10508-019-01591-z) contains supplementary material, which is available to authorized users.

This commentary refers to the article available at https://doi. org/10.1007/s10508-018-1377-2.

Vincent Savolainen

v.savolainen@imperial.ac.uk

1 Department of Life Sciences, Silwood Park Campus, Imperial College London, Ascot SL5 7PY, UK

2 Department of Life Sciences, South Kensington Campus, Imperial College London, London, UK

\section{Multiple Genes Underpin Same-Sex Sexual Behavior}

Before discussing the evidence for a potential link between the TRPC2 gene and SSSB in primates, and indeed all mammals, it is essential to clarify that any such link ought not to be interpreted as promoting a single "gay gene" theory of homosexuality (i.e., same-sex sexual partner preferences) and SSSB. Firstly, there is already a growing body of evidence for an epigenetic and polygenic underpinning of homosexuality and SSSB (Ratnu, Emami, \& Bredy, 2017; Rice, Friberg, \& Gavrilets, 2016; Sanders et al., 2017). Secondly, since it is the absence of functional TRPC2 that appears to facilitate heightened SSSB, it seems that the gene is not itself driving SSSB, but instead that it is perhaps underpinning same-sex aversion, which is inversely related but not inherently antithetical to SSSB. Finally, it is evident from the presence of SSSB in animals with functioning TRPC2 and VNO (for example, in rodents, spider monkeys, and bison; see Bagemihl, 1999; Busia, Denice, Aureli, \& Schaffner, 2018; Sommer \& Vasey, 2006) that the effect of TRPC2 pseudogenization (i.e., loss of function due to a premature stop codon) cannot completely explain the expression of the behavioral phenotype for SSSB.

Further support for the polygenic nature of SSSB derives from comparisons of TRPC2 with another gene, tryptophan hydroxylase 2 (TPH2). Initial work suggested that $T P H 2$, which facilitates 5-HT neurotransmitter synthesis and is critical for serotonergic neuron function, had a strong role in the modulation of SSSB (Liu et al., 2011; Zhang, Liu, \& Rao, 2013). These researchers reported that TPH2 KO males showed no significant preference for either males or females, in addition to showing significant increases in SSSB. This result was contrasted with TRPC $2 \mathrm{KO}$ males that, by comparison, exhibited only a reduced preference for females relative to males (Axel et al., 2002; Liu et al., 2011). However, subsequent attempts to replicate the effects of $T P H 2 \mathrm{KO}$ have questioned the connection between functional TPH2 and sexual partner preference (as a different type of sexual preference behavior experiment showed that both $\mathrm{TPH} 2 \mathrm{KO}$ and wild-type males preferred females), although SSSB 


\section{Stop Codon 71 \\ (TRPC2 Exon 13)}
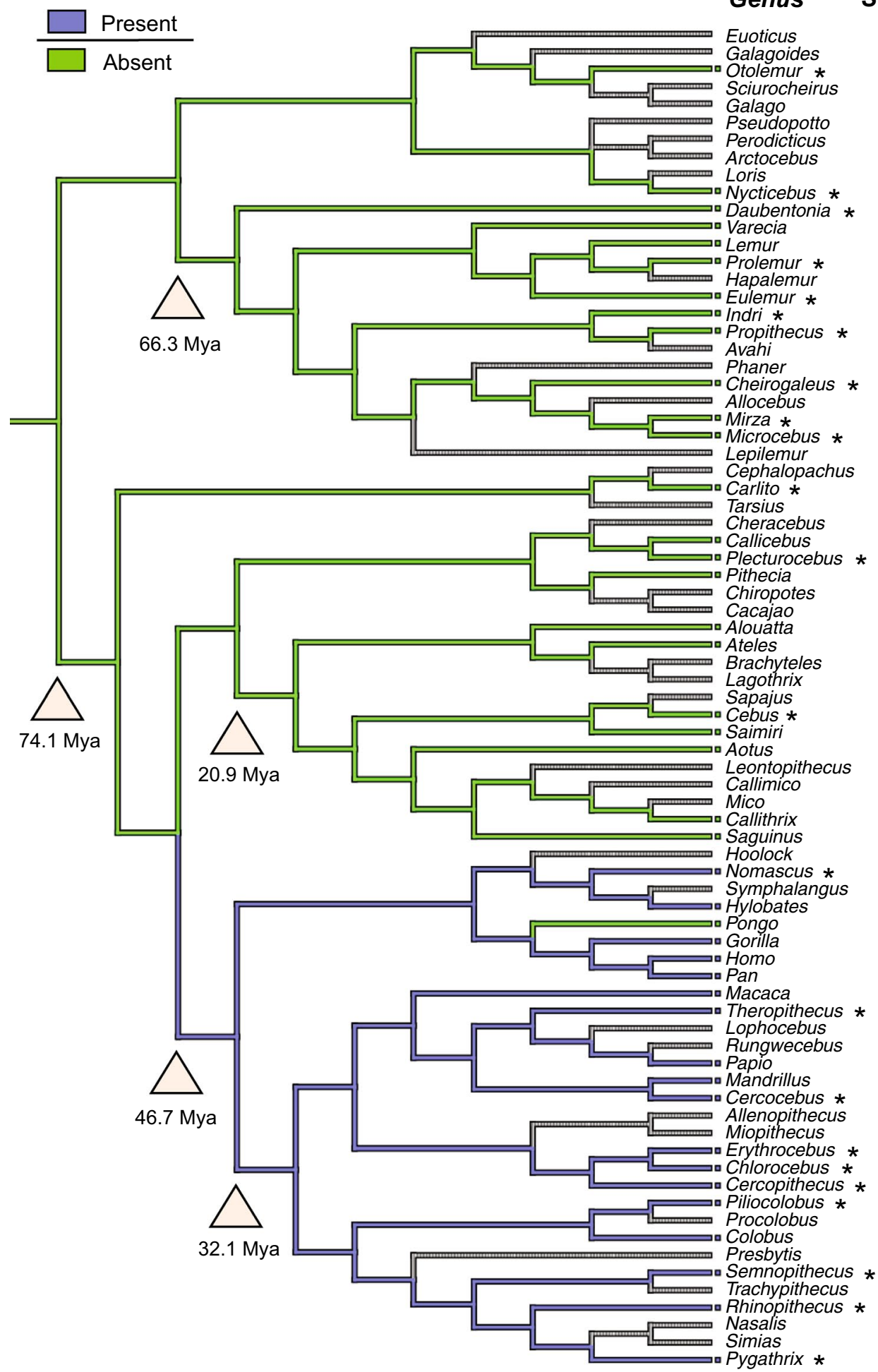

\section{Genus}

Euoticus Galagoides Dcolemur * Galago Peudopotto Perodicticus aubentonia

66.3 Mya
SSSB

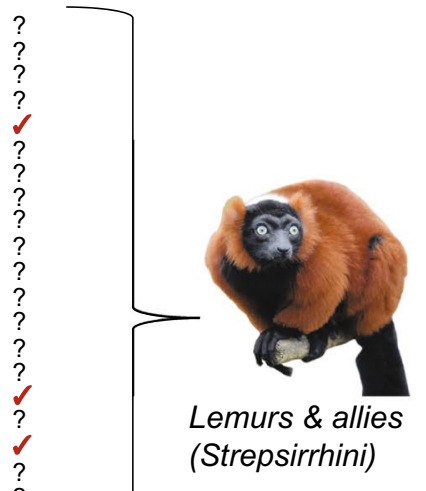

Tarsiers hin

(Tarsiidae)
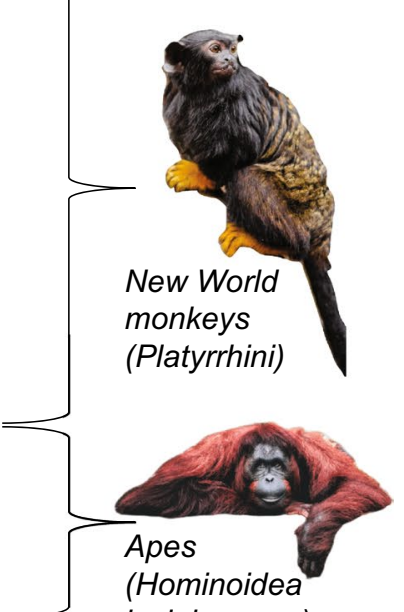

incl. humans) nevertheless increased in TPH2 KO males (Angoa-Pérez et al., 2015). Importantly, this contention brings into question the assumption of a direct inverse relationship, or degree of non-independence, between opposite-sex sexual behavior and SSSB. Attraction or propensity for SSSB might plausibly be independent of opposite-sex attraction and behavior, whereas a sexual preference for one sex versus the other must inherently be directly and inversely dependent. 
4 Fig. 1 Distribution of a premature stop codon in exon 13 of TRPC2 and SSSB across the phylogeny of primates. We found that the earliest stop codon in exon 13 of TRPC2 to appear in primates was at position 71, along the branch leading to Old World monkeys and apes (blue =stop codon present; green=stop codon absent; gray $=$ unknown). The presence of SSSB was determined from behavioral reports, with an uncertain status (indicated by a question mark) applied to genera without confirmed SSSB in the wild (Bagemihl, 1999; Carosi \& Visalberghi, 2002; Chandler, 1975; Fang, Dixson, Qi, \& Li, 2018; Fox, 2001; Grueter \& Stoinski, 2016; Huang, Zhou, Li, Huang, \& Wei, 2015; Moynihan, 1970; Poiani, 2010; Sommer \& Vasey, 2006). Evidence of SSSB in Colobus is taken from a pers. comm. of Teichroeb in Pfau et al. (2019). The phylogeny was taken from the Open Tree of Life online resource (Hinchliff et al., 2015) and the divergence times from Pozzi et al. (2014). Stars indicate sequences that have been provided here in addition to those reported in Pfau et al. (Photo credits: Flickr and David Gonzales, Pexels; Christine Wehrmeier, Unsplash) (Color figure online)

\section{TRPC2 in the VNO, and Same-Sex Sexual Behavior Across Primates}

The experimental evidence of TRPC2 KO mice, combined with the loss of TRPC2 in frequently SSSB-exhibiting cetaceans (Harvey, Dudzinski, \& Kuczaj, 2017; Sommer \& Vasey, 2006; Yu et al., 2010) and bats (Riccucci, 2011; Sugita, 2016; Yohe et al., 2017), provides a reasonable basis for supposing a homologous effect in Old World monkeys and apes (Catarrhini) as argued by Pfau et al. However, the evidence for such a connection is at present limited primarily by taxon sampling. Previous reconstructions establishing the ancestral pseudogenization of TRPC 2 only assessed up to 15 species as representatives of the respective 77 extant primate genera (Liman \& Innan, 2003; Zhang \& Webb, 2003). After mining GenBank to retrieve all possible sequences of TRPC2, we performed an updated reconstruction using 42 species of separate primate genera (Fig. 1 and supplementary information). We focused on a stop codon at position 71 in exon 13 of TRPC2, which was postulated by Pfau et al. to represent the ancestral loss of TRPC2 function and hypothetical increase in SSSB in Old World monkeys. Using this larger sampling, and examining the distribution of this stop codon, we found that indeed the likely point of pseudogenization was after the split between the New World monkeys (Platyrrhini) versus Old World monkeys and apes (Fig. 1), as postulated by Pfau et al. We estimated this stop codon to have appeared between 46.7 and 32.1 million years ago (Mya; Fig. 1), slightly earlier than what was reported in Pfau et al. (i.e., 25 Mya). Other stop codons are found in exon 13 (supplementary information), although their distribution in fewer lineages would indicate that they appeared more recently than the premature stop at position 71. Ancestral state reconstructions for all stop codons indicated in the supplementary information were conducted using parsimony in Mesquite 3.6 (Maddison \& Maddison, 2018). However, the pattern of SSSB and lost TRPC2 function in primates does not map so easily.
SSSB has only been observed in three genera within Strepsirrhini, the lesser bushbabies (Galago), brown lemurs (Eulemur), and sifaka (Propithecus) (Bagemihl, 1999; Chandler, 1975), but in New World monkeys, at least 7 out of 19 genera are reported as exhibiting SSSB (Bagemihl, 1999; Carosi \& Visalberghi, 2002; Dixson, 2012; Moynihan, 1970). Furthermore, the functionality of TRPC 2 in New World monkeys is still unclear. For example, spider monkeys (Ateles) appear to possess functioning TRPC2 and yet also exhibit SSSB (Busia et al., 2018). Squirrel monkeys (Saimiri) and Atlantic forest marmosets (Callithrix) also perform SSSB, but they have an incomplete VNO with a reduced vomeronasal epithelium (VNE), through which TRPC2 might not be able to express the phenotype for increased samesex aversion (Pfau et al., 2019). Similarly, a reduced VNE has been reported in capuchins (Cebus), and interrupted or interspersed VNE in tamarins (Saguinus) and lion tamarins (Leontopithecus) (Smith et al., 2011), with all three species exhibiting SSSB (Bagemihl, 1999; Carosi \& Visalberghi, 2002; Moynihan, 1970). Conversely, owl monkeys (Aotus) are reported to have a complex VNO (Pfau et al., 2019) and do not seem to exhibit SSSB (Hunter \& Dixson, 1983), although the VNO of owl monkeys has also been described as small and unlikely to play a role in communication (Hunter, Fleming, \& Dixson, 1984). Similarly, Smith et al. (2011) showed that SSSB-expressing lion tamarins possess a thicker VNE than owl monkeys (and described the owl monkey VNE as being poorly developed), thereby undermining the notion of VNE layers mediating TRPC2 functionality and consequently SSSB. Both of the aforementioned VNO studies emphasize that the owl monkey VNO is similar in microanatomy to that of tamarins, an SSSB-exhibiting genus, and suggest that spider monkeys, which also exhibit SSSB, have the most similar VNO to the lemurs, which rarely, if ever, exhibit SSSB (Hunter et al., 1984; Smith et al., 2011). The pattern of SSSB expression in New World monkeys, therefore, cannot comfortably be coupled with variation in overall VNO structure.

\section{Absence of Evidence for Same-Sex Sexual Behavior is not Evidence of Absence}

As mentioned above, SSSB is reported among New World monkeys in 7 out of 19 genera (Bagemihl, 1999; Carosi \& Visalberghi, 2002; Dixson, 2012; Moynihan, 1970), but is believed to be substantially less frequent and less intense than in Old World monkeys and apes (Dixson, 2012). Although likely to be broadly true, caution should be taken when making such comparative statements, since studies are often non-equivalent, with different objectives, sampling effort, and variables; an analysis of mounting behavior alone might assess only a subset of mount frequency, latency, copulatory duration, intromission, and ejaculation. Functionality of TRPC2 might better predict variation in frequency of SSSB, rather than presence-absence, 
but comparative studies of frequency and intensity of SSSB between primate genera are limited.

Generally, behavioral field studies of SSSB have only recently been substantially conducted, with early reports often taking the form of opportunistic anecdotes (Sommer \& Vasey, 2006). For example, a recent study of spider monkeys reported the opportunistic observation of three homosexual couplings of one male with three different male partners as "low levels" of SSSB (Busia et al., 2018; Pfau et al., 2019), whereas the evidence for SSSB in wild Sumatran orangutans (Pongo) is comprised of opportunistic anecdotes involving mere two copulatory mounts (Fox, 2001). Furthermore, the relatively low frequencies of SSSB in primates other than Old World monkeys and apes do not explain the indisputably high frequencies observed in other mammals with functioning TRPC2 and VNO, such as bison and red deer (Sommer \& Vasey, 2006). We further argue that one cannot rely on behavioral studies unless they have been explicitly designed to assess SSSB, since without a mandate to observe SSSB, studies that report low frequencies or even absences may potentially be suffering from long-standing homophobic biases, or even the simple mistake of sexing individuals by presuming heterosexuality when any sexual coupling between individuals is observed (Bailey et al., 2016; Sommer \& Vasey, 2006).

\section{Can a Premature Stop Codon in TRPC2 be Compensated for?}

$T P R C 2$ is considered non-functional because of a premature stop codon, but newly discovered mechanisms have shown that the function(s) of one gene with premature stop codons are frequently compensated for by the upregulation of orthologues from the same gene family (Peng, 2019). This discovery initially hinged on the fact that deleterious mutations with premature stop codons often only give a reduction in the relevant phenotype compared with the effects of acute knockdowns (reduced expression) of the same genes (Rossi et al., 2015). It now turns out that RNA transcripts with premature stop codons are preferentially degraded and gene family orthologues upregulated (ElBrolosy et al., 2019; Ma et al., 2019). This compensatory mechanism requires transcription of the mutant gene (RNA capping), and also the COMPASS complex, which catalyzes the methylation of histones at the transcriptional start site of upregulated gene orthologue family members. If there is no transcription of the mutant gene (for example, it is deleted entirely), there is no genetic compensation. Thus, a still unaddressed but critical issue is: could other TRPC gene orthologues be partially rescuing, perhaps tissue specifically, the phenotype of the TRPC2 gene KOs with premature stop codons?

\section{Conclusion}

To fully understand any behavior (here SSSB), it is important to distinguish between proximate hypotheses ("how it works") from ultimate hypotheses (the "why" question). We note that Pfau et al. refer to the link between non-functional TRPC2 and SSSB, and its loss in primate lineages, as an ultimate explanation; however, these are instead proximate hypotheses. Ultimate explanations require the expected fitness consequences of trait variation to be defined (ScottPhillips, Dickins, \& West, 2011). Since the proximate link between TRPC2 and SSSB in primates remains unclear, we believe its clarification should be a priority for investigators in this field. This is not to say that the proposed explanation of group cohesion through socially adaptive functions facilitated by SSSB (which is an ultimate hypothesis) and/or pleiotropy with reduced aggression is unappealing, but we also note that a preliminary question, for example, would be to ask why TRPC 2 loss has not then been documented in the multi-male multi-female group-living diurnal lemurs, squirrel monkeys, and capuchins (Sussman, 1999).

Given recent progress on genome editing in primates (e.g., CRISPR; Zhou et al., 2019), researchers might consider the possibility of TRPC $2 \mathrm{KO}$ in New World monkeys or lemurs, although by deleting the gene entirely and not by introducing premature stop codons. If Pfau et al.'s theory is true, then those KO mutants should exhibit increased SSSB. One might even attempt to rescue the function of $T R P C 2$ in an Old World monkey or ape and thereby expect suppression of SSSB, given that the true redundancy of their VNO has been contended (D'Aniello, Semin, Scandurra, \& Pinelli, 2017). These investigations would need effective ethical oversight, not only because of animal welfare, but also because under no circumstances should TRPC2 be advocated as a way to "cure" homosexuality. SSSB is likely under the control of multiple genes (Ratnu et al., 2017; Rice et al., 2016; Sanders et al., 2017), but linking TRPC2, VNO, and SSSB represents an exciting hypothesis by which genes can fine-tune the development of complex behaviors.

\section{Compliance with Ethical Standards}

Conflict of interest All authors declare that they have no conflict of interest. 
Open Access This article is distributed under the terms of the Creative Commons Attribution 4.0 International License (http://creativeco mmons.org/licenses/by/4.0/), which permits unrestricted use, distribution, and reproduction in any medium, provided you give appropriate credit to the original author(s) and the source, provide a link to the Creative Commons license, and indicate if changes were made.

\section{References}

Angoa-Pérez, M., Herrera-Mundo, N., Kane, M. J., Sykes, C. E., Anneken, J. H., Francescutti, D. M., \& Kuhn, D. M. (2015). Brain serotonin signaling does not determine sexual preference in male mice. PLoS ONE, 10, 1-16. https://doi.org/10.1371/ journal.pone.0118603.

Axel, R., Yu, C. R., Zufall, F., Leypold, B. G., Leinders-Zufall, T., \& Kim, M. M. (2002). Altered sexual and social behaviors in trp2 mutant mice. Proceedings of the National Academy of Sciences USA, 99, 6376-6381. https://doi.org/10.1073/pnas.082127599.

Bagemihl, B. (1999). Biological exuberance: Animal homosexuality and natural diversity. New York: Macmillan.

Bailey, J. M., Vasey, P. L., Diamond, L. M., Breedlove, S. M., Vilain, E., \& Epprecht, M. (2016). Sexual orientation, controversy, and science. Psychological Science in the Public Interest, 17, 45-101. https://doi.org/10.1177/1529100616637616.

Busia, L., Denice, A. R., Aureli, F., \& Schaffner, C. M. (2018). Homosexual behavior between male spider monkeys (Ateles geoffroyi). Archives of Sexual Behavior, 47, 857-861. https:// doi.org/10.1007/s10508-018-1177-8.

Carosi, M., \& Visalberghi, E. (2002). Analysis of tufted capuchin (Cebus apella) courtship and sexual behavior repertoire: Changes throughout the female cycle and female interindividual differences. American Journal of Physical Anthropology, 118, 11-24. https://doi.org/10.1002/ajpa.10083.

Chandler, C. F. (1975). Development and function of marking and sexual behavior in the malagasy prosimian primate, Lemur fulvus. Primates, 16, 35-47. https://doi.org/10.1007/BF02381798.

D’Aniello, B., Semin, G. R., Scandurra, A., \& Pinelli, C. (2017). The vomeronasal organ: A neglected organ. Frontiers in Neuroanatomy, 11, 70. https://doi.org/10.1038/srep44295.

Dixson, A. F. (2012). Primate sexuality (2nd ed.). Oxford: Oxford University Press. https://doi.org/10.1093/acprof:osobl/97801 99544646.003.0006.

El-Brolosy, M. A., Kontarakis, Z., Rossi, A., Kuenne, C., Günther, S., Fukuda, N., ... Stainier, D. Y. R. (2019). Genetic compensation triggered by mutant mRNA degradation. Nature, 568, 193-197. https://doi.org/10.1038/s41586-019-1064-z.

Fang, G., Dixson, A. F., Qi, X. G., \& Li, B. G. (2018). Male-male mounting behaviour in free-ranging golden snub-nosed monkeys (Rhinopithecus roxellana). Folia Primatologica, 89, 150-156. https://doi.org/10.1159/000487004.

Fox, E. A. (2001). Homosexual behavior in wild Sumatran orangutans (Pongo pygmaeus abelii). American Journal of Primatology, $55,177-181$.

Grueter, C. C., \& Stoinski, T. S. (2016). Homosexual behavior in female mountain gorillas: Reflection of dominance, affiliation, reconciliation or arousal? PLOS ONE, 11, 1-13. https://doi. org/10.1371/journal.pone.0154185.

Harvey, B. S., Dudzinski, K. M., \& Kuczaj, S. A. (2017). Associations and the role of affiliative, agonistic, and socio-sexual behaviors among common bottlenose dolphins (Tursiops truncatus). Behavioural Processes, 135, 145-156. https://doi.org/10.1016/j. beproc.2016.12.013.

Hinchliff, C. E., Smith, S. A., Allman, J. F., Burleigh, J. G., Chaudhary, R., Coghill, L. M., ... Cranston, K. A. (2015). Synthesis of phylogeny and taxonomy into a comprehensive tree of life. Proceedings of the National Academy of Sciences USA, 112, 12764-12769. https://doi.org/10.1073/pnas.1423041112.

Huang, C., Zhou, Q., Li, Y., Huang, Z., \& Wei, X. (2015). Nonconceptive sexual behavior and its function in an unusually composed group of Francois langurs (Trachypithecus francoisi) in Guangxi, China. Vietnamese Journal of Primatology, 2, 29-38.

Hunter, A. J., \& Dixson, A. F. (1983). Anosmia and aggression in male owl monkeys (Aotus trivirgatus). Physiology \& Behavior, 30, 875-879. https://doi.org/10.1016/0031-9384(83)90251-2.

Hunter, A. J., Fleming, D., \& Dixson, A. F. (1984). The structure of the vomeronasal organ and palatine ducts. Journal of Anatomy, $138,217-225$.

Kimchi, T., Xu, J., \& Dulac, C. (2007). A functional circuit underlying male sexual behaviour in the female mouse brain. Nature, 448, 1009-1014.

Liman, E. R., \& Innan, H. (2003). Relaxed selective pressure on an essential component of pheromone transduction in primate evolution. Proceedings of the National Academy of Sciences USA, 100, 3328-3332. https://doi.org/10.1073/pnas.0636123100.

Liu, Y., Jiang, Y. A., Si, Y., Kim, J. Y., Chen, Z. F., \& Rao, Y. (2011). Molecular regulation of sexual preference revealed by genetic studies of 5-HT in the brains of male mice. Nature, 472, 95-100. https://doi.org/10.1038/nature09822.

Ma, Z., Zhu, P., Shi, H., Guo, L., Zhang, Q., Chen, Y., ... Chen, J. (2019). PTC-bearing mRNA elicits a genetic compensation response via Upf3a and COMPASS components. Nature, 568, 259-263. https://doi.org/10.1038/s41586-019-1057-y.

Maddison, W. P., \& Maddison, D. R. (2018). Mesquite: A modular system for evolutionary analysis (Version 3.51). Retrieved 30 July, 2019 from https://www.mesquiteproject.org/.

Moynihan, M. (1970). Some Behavior patterns of Platyrrhine monkeys II. Saguinus geoffroyi and some other Tamarins. Smithsonian Contributions to Zoology, 28, 1-77.

Peng, J. (2019). Gene redundancy and gene compensation: An updated view. Journal of Genetics and Genomics, 20, 329-333. https://doi.org/10.1016/j.jgg.2019.07.001.

Pfau, D., Jordan, C. L., \& Breedlove, S. M. (2019). The de-scent of sexuality: Did loss of a pheromone signaling protein permit the evolution of same-sex sexual behavior in primates? Archives of Sexual Behavior. https://doi.org/10.1007/s10508-018-1377-2.

Poiani, A. (2010). Animal homosexuality: A biosocial perspective. Cambridge: Cambridge University Press.

Pozzi, L., Hodgson, J. A., Burrell, A. S., Sterner, K. N., Raaum, R. L., \& Disotell, T. R. (2014). Primate phylogenetic relationships and divergence dates inferred from complete mitochondrial genomes. Molecular Phylogenetics and Evolution, 75, 165-183. https://doi.org/10.1016/j.ympev.2014.02.023.

Ratnu, V. S., Emami, M. R., \& Bredy, T. W. (2017). Genetic and epigenetic factors underlying sex differences in the regulation of gene expression in the brain. Journal of Neuroscience Research, 95, 301-310. https://doi.org/10.1002/jnr.23886.

Riccucci, M. (2011). Same-sex sexual behaviour in bats. Hystrix, 22, 139-147. https://doi.org/10.4404/Hystrix-22.1-4478.

Rice, W. R., Friberg, U., \& Gavrilets, S. (2016). Sexually antagonistic epigenetic marks that canalize sexually dimorphic development. Molecular Ecology, 25, 1812-1822. https://doi.org/10.1111/ mec. 13490.

Rossi, A., Kontarakis, Z., Gerri, C., Nolte, H., Hölper, S., Krüger, M., \& Stainier, D. Y. R. (2015). Genetic compensation induced by deleterious mutations but not gene knockdowns. Nature, 524, 230-233. https://doi.org/10.1038/nature14580.

Sanders, A. R., Beecham, G. W., Guo, S., Dawood, K., Rieger, G., Badner, J. A., ... Martin, E. R. (2017). Genome-wide association study of male sexual orientation. Scientific Reports, 7, 1-6. https ://doi.org/10.1038/s41598-017-15736-4. 
Scott-Phillips, T. C., Dickins, T. E., \& West, S. A. (2011). Evolutionary theory and the ultimate-proximate distinction in the human behavioral sciences. Perspectives on Psychological Science, 6, 38-47. https://doi.org/10.1177/1745691610393528.

Smith, T. D., Garrett, E. C., Bhatnagar, K. P., Bonar, C. J., Bruening, A. E., Dennis, J. C., ... Morrison, E. E. (2011). The vomeronasal organ of New World monkeys (platyrrhini). Anatomical Record, 294, 2158-2178. https://doi.org/10.1002/ar.21509.

Sommer, V., \& Vasey, P. L. (Eds.). (2006). Homosexual behaviour in animals: An evolutionary perspective. Cambridge: Cambridge University Press.

Sugita, N. (2016). Homosexual fellatio: Erect penis licking between male bonin flying foxes pteropus pselaphon. PLoS ONE, 11, 1-9. https://doi.org/10.1371/journal.pone.0166024.

Sussman, R. W. (1999). Primate ecology and social structure. Needham Heights, MA: Pearson Custom Publishing.

Yohe, L. R., Abubakar, R., Giordano, C., Dumont, E., Sears, K. E., Rossiter, S. J., \& Dávalos, L. M. (2017). Trpc2 pseudogenization dynamics in bats reveal ancestral vomeronasal signaling, then pervasive loss. Evolution, 71, 923-935. https://doi.org/10.1111/ evo.13187.

Yu, L., Jin, W., Wang, J. X., Zhang, X., Chen, M. M., Zhu, Z. H., ... Zhang, Y. P. (2010). Characterization of TRPC2, an essential genetic component of VNS chemoreception, provides insights into the evolution of pheromonal olfaction in secondary-adapted marine mammals. Molecular Biology and Evolution, 27, 1467-1477. https ://doi.org/10.1093/molbev/msq027.

Zhang, J., \& Webb, D. (2003). Evolutionary deterioration of the vomeronasal pheromone transduction pathway in catarrhine primates. Proceedings of the National Academy of Sciences USA, 100, 8337-8341. https://doi.org/10.1097/CPM.0b013e31822bdd9d.

Zhang, S., Liu, Y., \& Rao, Y. (2013). Serotonin signaling in the brain of adult female mice is required for sexual preference. Proceedings of the National Academy of Sciences USA, 110, 9968-9973. https ://doi.org/10.1073/pnas.1220712110.

Zhou, Y., Sharma, J., Ke, Q., Landman, R., Yuan, J., Chen, H., ... Yang, S. (2019). Atypical behaviour and connectivity in SHANK3mutant macaques. Nature, 570, 326-331. https://doi.org/10.1038/ s41586-019-1278-0.

Publisher's Note Springer Nature remains neutral with regard to jurisdictional claims in published maps and institutional affiliations. 